\title{
A Corpus Study of Politeness Principle in Desperate Housewife ${ }^{*}$
}

\author{
Jingyu Deng \\ Beijing Information Science and Technology University, Beijing, China \\ Xiaoliang Zhou \\ Beijing Information Science and Technology University, Beijing, China
}

\begin{abstract}
Since it was broadcast, the pragmatic studies of the American TV series Desperate Housewife (DH) have become popular. But a majority of those studies focused on Cooperation Principle and the Theory of Conversational Implication; only a few scholars studied Politeness Principle (PP). Besides, most of the pragmatic studies used the qualitative, instead of the quantitative, approach. To solve these problems, this research builds up a corpus based on Leech's definition of PP, with the first season of DH as the object, the PP as the theoretical basis. Then, the PP conversations in the corpus is researched with the quantitative method. Finally, the conclusion is reached that Tact Maxim is the most frequently used maxim while Modesty Maximis the least.
\end{abstract}

Index Terms-PP, quantitative study, corpus, Desperate Housewife

\section{INTRODUCTION}

Since the American TV series Desperate Housewife $(D H)$ was broadcast, it has caught many linguists' attention. It is made up of eight seasons and each season has twenty-three episodes. As a representative of the modern American daily life with lots of conversations in each episode, it can be regarded as a plentiful corpus for language scholars to study. Therefore, to some pragmatic scholars, it is a good studying material.

Among all the relevant studies, most pragmatic scholars focus on the meanings of conversations in this series, which means, the Cooperation Principle and the Theory of Conversational Implication are the main theories in their studies. Only a minority of scholars do their researches on the application of expressions in it, which is they study the Politeness Principle (PP) in this TV series. Besides, among the minority studies, the Principle is always in a subordinate place. Nearly none of them regard the PP as an independent theory to do researches. Hence, the researches on the application of expressions in $\mathrm{DH}$ are not enough and the studies about the Principle as an independent theory are almost blank. Also, the majority of the pragmatic scholars are using the qualitative approach, seldom using the quantitative approach. As the quantitative approach is a necessary supplement to qualitative approach and also is more objective than qualitative approach; therefore, using quantitative approach to study PP in $\mathrm{DH}$ is another blank.

The PP will be the independent theory in this paper, and the quantitative approach will be used as the researching method in this study. These are also the original points in this research. But, the quantitative approach is a generalized cognition, so choosing a specific approach is more feasible in that case. Since the corpus study is one of the quantitative approaches and it is a more objective approach, the corpus study method as a specific quantitative approach will be chosen as the researching method. In conclusion, this research will use corpus study method to study the PP in $\mathrm{DH}$.

Through the study, a statistic result of the frequency of PP used in $D H$ will come out, and the result will be made a proportion after that. Finally, the objective of this research is to use appropriate reasons to explain why such results come out and to explore how often people express their politeness in their daily life in modern American culture.

When it comes to the feasibility of this research, there are several evidences. Firstly, there are lots of conversations in $D H$ and those conversations can be regarded as a plentiful corpus. Thus, it can easily provide study materials for this study. Secondly, the PP is a mature theory and is has been applied in many conversations in $D H$. Hence, it is also feasible to do researches about PP in that TV series. Thirdly, there are existed some former relevant studies about PP in $\mathrm{DH}$ and about using corpus study method to do researches, though not much but enough to be the reference in this study. Finally, the statistic skill is very helpful while doing the statistic work and the proportion making work. In a word, it is definitely feasible to carry out this research.

As for the significance of this study, it has both theoretical and practical significances. In the theoretical part, this study as a part of the pragmatic study about $\mathrm{DH}$, it will enrich this study field to some extent. Through this study, the above mentioned two research blanks will be filled and the pragmatic research areas will be broadened to some extent. Thus, it will be much helpful to know more about PP. While in the practical part, we can understand more about

\footnotetext{
* This paper was supported by the foundation of Beijing Information Science and Technology University with the Project NO.1335023 and financial code 5026010930 .
} 
American culture and how the PP is applied in their daily expressions.

In short, this research is going to use corpus study method to study the PP in $D H$. Since it has a clear objective and useful methods, this study will be a feasible one. After the result of this study comes out, the significance of this study will be clearly presented.

\section{A CRITIQUE OF PP}

PP becomes important because it is a broader, socially and psychologically oriented application of pragmatic principle. (Leech, 1983, p. 80)

\section{Brief Introduction to PP}

The PP was first officially put forward by Geoffrey Leech, but the study of this principle began in earlier years. Before Leech's study, Goffman, Brown \& Levinson, Lakoff and other scholars have already begun their researches.

Later, Goffman's Face Theory has been heavily utilized by Brown \& Levinson (Gerard, 2012, p. 102). They divided the notion of face into two parts. One is called positive face, another is called negative face. They claimed that in doing politeness, people have both negative face needs and positive face needs (Gerard, 2012, p. 102), which means people have the desire to protect one's positive face and negative face (Sharon \& Caroline, 2011, p. 120). Thus, certain behaviors are required in order to satisfy the need of people's face. "The term 'Politeness' should be applied beyond the prescriptions of etiquette manuals to cover a whole range of pragmatic strategies aimed at the reduction of fact-threats (Jary, 1998, p. 18).”

Finally, based on all the above opinions, the cognition of PP was put forward by Leech. "According to Leech (1983), there is a PP with conversational maxims. He lists six maxims: tact, generosity, approbation, modesty, agreement and sympathy. The first and second form a pair, as do the third and fourth.” (Cutting, 2007, p. 49)

\section{The Achievements and Limitations of Former Studies}

Many studies focus on the meanings of conversations in $D H$. Those scholars have already studied lots of conversations in $\mathrm{DH}$, and have found out a common phenomenon, namely, the characters in $\mathrm{DH}$ often violate the Cooperation Principle deliberately when they are in conversations. This kind of common phenomenon will produce implications while in conversations, which means the characters' conversations follow the Theory of Conversational Implication. These study results are just in coincidence with Grice's opinion, which is "the implicature is not carried by what is said, but only by the saying of what is said" (Grice, 1975, p. 58).

However, about the researches of PP in $\mathrm{DH}$, the situation is complicated. The studies of PP are often combined with other studies, or always being a part of other researches. Only a few scholars study the PP only in their researches. In other words, since the PP was put forward originally in order to make the Cooperation Principle more perfect, many scholars take PP as a part of the Conversational Implication Theory studies.

Since the studies about PP as an independent theory in $D H$ can hardly find, this research field is almost in blank now. So the problems about the PP in $\mathrm{DH}$ are still unsolved. This is one of the limitations of all the already existing pragmatic studies essays about $D H$. In addition, quite a few of the studies are using the qualitative approach, seldom using the quantitative approach. As the quantitative approach is more objective than the qualitative approach sometimes, the quantitative approach is also needed while doing researches, in order to get more appropriate study results. The two approaches will be discussed more in details later. Hence, lack of using the quantitative approach to study $D H$ is another limitation of the existed studies.

\section{Leech's Theory and Definitions of PP}

The study about PP has gone through many years and lots of scholars have done researches on it. Among those scholars, Goffman, Brown \& Levinson, Lakoff and Leech are the famous representatives, especially Leech, who was the first person to put forward the cognition of PP and gave the clear definition. After Leech's theory came out, other scholars also did many researches on this study field, but none of them has achieved the success as Leech did. Therefore, Leech's theory is considered as the authority of this study field now. What's more, Leech's theory is more completed than others' theories. Not only he gave better definitions in his theory but also classified his theory into six maxims which can explain many conversational situations. In a word, Leech's theory can explain conversational situations more in details than others' theories. Hence, choosing Leech's theory as the criterion to study is a good choice.

About the six maxims, they are defined respectively as Tact Maxim, Generosity Maxim, Approbation Maxim, Modesty Maxim, Agreement Maxim and Sympathy Maxim. The definitions of those maxims are as following.

(1) Tact Maxim

(a) Minimize cost to others

(b) Maximize benefit to others

(2) Generosity Maxim

(a) Minimize benefit to self

(b) Maximize cost to self.

(3) Approbation maxim

(a) Minimize dispraise of others

(b) Maximize praise of others

(4) Modesty Maxim 
(a) Minimize praise of self

(b) Maximize dispraise of self

(5) Agreement Maxim

(a) Disagreement between self and others

(b) Maximize agreement between self and others

(6) Sympathy Maxim

(a) Minimize antipathy between self and others

(b) Maximize sympathy between self and others.” (Ma, 1995; Zhu, 2012)

\section{Methodology}

Since the theory in this study has been discussed, the study methods also need to be mentioned. Among the researches about $\mathrm{DH}$, quantitative approach studies are rare. So as a typical quantitative approach, corpus study method will be introduced and how to use it to do this study will also be talked about.

As the statement above, there are existing two common researching methods. One is qualitative approach, the other is the quantitative approach. In order to have a clear idea about the qualitative approach and the quantitative approach, these two approaches will be analyzed in a contrast as follows:

"The qualitative approach has been widely adopted in the study of linguistics. In the process of qualitative analysis, qualitative researches aim to study individuals and events in their natural settings. (Tetnowski \& Damico, 2001) That is to say, rather than attempting to control contextual factors (extraneous variables) through the use of laboratories or other artificial environments, it is often process-oriented, or open ended.

As we can see from the above, the quantitative approach is an obtrusive and generalizable method, involving controlled measurement and replicable data, which makes it more objective than the qualitative approach. So the quantitative approach will be chosen in this study.

But, the quantitative approach is a generalized cognition. Thus, a specific approach will be more feasible in that circumstance. So the corpus study method will be a good choice. Reasons for chose this method is that, corpus study emphasizes on language data collection and analysis, which has the ability to manage and analysis the study object systematically. Thus, it can be viewed as a typical quantitative approach in language study. Besides, it is a sum of all the words which are used by certain language users. And those certain language users have some common characteristics in using their language. So the corpus study method is a good way to study those common characteristics. In conclusion, this study is going to use the corpus study method to do the research.

As for the object of this study, it will be the script of the first season in $\mathrm{DH}$. The first season is selected randomly, which helps reduce the error and makes the study more objective. Besides, there are lots of polite sentences in the first season, which provide enough language materials for this study.

According to the corpus study method, to build up a corpus, data selecting criteria and language materials are two necessary conditions. As we have mentioned before that Leech's theory will be the corpus data selecting criteria and the script of the first season will be the study object. Thus, based on the definitions of Leech's six maxims strictly, each sentence will be read and checked to find out if it fits the criteria. Then, collecting all the qualified sentences and the corpus will be built up.

When the corpus building work is finished, the statistic work will begin according to the data in the corpus. The frequency of each maxim applied will be counted and will be made a proportion. After analyzing the results, we will find the reasons why such results come out and how often people express their politeness in modern American daily life.

In a word, in this study, the definition of the PP and the six maxims will be the criterion to build a corpus. The sentences in which PP is applied in the first season of $D H$ are selected as the language data in the corpus, and those data are selected from the script of the first season of $D H$. After the corpus build up, the data in the corpus will be counted and later analyzed.

\section{RESULTS}

As we have mentioned before that we will use corpus study method to do the research on the first season of $D H$ in this study. Thus, a corpus whose data are selected from the script of the first season should be built up at first. The corpus in this study will be seen in the later appendix part and its name is "The Corpus of PP in DH Season I".

Because the data of this corpus should be selected from the script of the first season of $D H$, the script should be studied first. As the script checking result shows, there are about 13333 segments of conversations in the script of the first season, each episode having about more than 500 to more than 600 segments. Due to the fact that the segments are not the completed sentences or conversations, they should be reorganized into the completed in order to be more convenient in doing research. Also, the reorganization work will be much helpful in following statistic work, which will make the statistic result more precise. Hence, a reorganization work is necessary before doing statistic work.

Following the above stated methods and steps, the author did the selecting data work first based on the above mentioned standard. Later, the author reorganized all those selected data into 966 conversations, and there are about 
more than 30 to more than 50 conversations in each episode. Each conversation contains at least one complete sentence and applies at least one of Leech's six maxims. Then, the author did the statistic work and the statistic result can be seen as following. Table 1 shows the frequency of each maxim applied in DH Season One respectively, and a total number of all will also be displayed.

TABLE 1

THE Statistic Result of LeECH’s Six MAXiM ApPLy in DH (SEASON ONE)

\begin{tabular}{|l|l|l|}
\hline Name of Maxim & Abbreviation of Maxim & Frequency \\
\hline Tact Maxim & TM & 778 \\
\hline Generosity Maxim & GM & 97 \\
\hline Approbation Maxim & ApM & 504 \\
\hline Modesty Maxim & MM & 3 \\
\hline Agreement Maxim & AgM & 95 \\
\hline Sympathy Maxim & SM & 156 \\
\hline Total & T & 1633 \\
\hline
\end{tabular}

After the statistic result came out, the author did the final work, which was making the proportion according to the frequency numbers. The proportion making result can also be seen in the following. Table 2 show the frequency numbers, the precise proportion result and the approximately proportion result. The approximately results will be more useful than the precise results when discussing the reasons why such numbers and proportions appeare. But this kind of discussion will be discussed in the next part.

TABLE 2.

THE PROPORTIONS OF LEECH'S SIX MAXIMS APPLY IN DH

\begin{tabular}{|l|l|l|l|l|l|l|l|}
\hline Name & TM & GM & ApM & MM & AgM & SM & T \\
\hline Frequency & 778 & 97 & 504 & 3 & 95 & 156 & 1633 \\
\hline Proportion & $778: 97: 504: 3: 95: 156$ \\
\hline $\begin{array}{l}\text { Approximately } \\
\text { Proportion }\end{array}$ & $750: 100: 500: 1: 100: 150$ & & \\
\hline
\end{tabular}

Obviously, we can see from the above two Tables that the PP is applied in conversations of DH (Season One) very often, because the total number is large. And Tact Maxim is the most useful maxim among six maxims, followed by Approbation Maxim, which is the second welcomed maxim. Then Sympathy Maxim takes the third place. Next are Generosity Maxim and Agreement Maxim. Those two have almost the same frequency. Finally, Modesty Maxim is the least used maxim, whose frequency is much less than any other five maxims.

\section{DISCUSSION}

Leech pointed out that "not all of the maxims are equally important" (Zhu, 2012, p. 9), which means some maxims will be used more and some will be used less. In this study, the statistic result is in coincidence with Leech's opinion. As we can see from the former Tables, Tact Maxim is the most useful maxim, followed by Approbation Maxim. These two maxims are used much more than the other four maxims. Besides, Generosity Maxim, Agreement Maxim and Sympathy Maxim are used about the same. But Modesty Maxim is the least useful maxim, which is nearly none. Thus, we may draw a conclusion that Tact Maxim and Approbation Maxim are used very frequently when people show their politeness. Other three maxims are in the middle place. But Modesty Maxim is not welcomed when expressing politeness.

As for the reasons why some maxims are used more and some used less, we need to discuss each maxim in details.

The first one which should be discussed is Tact Maxim. Because Tact Maxim is related to benefit and cost, in order to show politeness, people prefer to use Tact Maxim to benefit others most or to cost others least. So Tact Maxim can bring people most benefits and people like this maxim a lot. That's why Tact Maxim is used so widely and its frequency is the top one in this study. The second one that would be talked about is Generosity Maxim. Generosity Maxim is also concerned about benefit and cost, but different from Tact Maxim, it considers about oneself. To show politeness, people have to cost themselves most and benefit themselves least. However, this is a kind of behavior which is against human's nature. Thus, people prefer to use it less than to use Tact Maxim when expressing politeness. In this study, the proportion shows the frequency of using Tact Maxim is about more than seven times as the frequency of using Generosity Maxim, which is coincidence with the analysis result.

The third one which should be mentioned is Approbation Maxim, which is the second most popular maxim among the six. Approbation Maxim is concerned about praising and dispraising others. It seems a nature that people like to praise by others and don't like to be dispraised. Therefore, when showing politeness, praise others is an excellent way. But if the situation is not allowed to praise, then dispraise others the least is also another good way to show politeness. That's the reason for Approbation Maxim is so welcomed by people. Then Modesty Maxim will be put forward. It is amazing that the frequency of Modesty Maxim is such low. The Modesty Maxim is also related to praise and dispraise, but different from Approbation Maxim, it is concerned about self. Normally, when people dispraise themselves, it may have the same effect to praise others. That is why that Modesty Maxim has the effect to express politeness. But 
surprisingly, this maxim is used barely in this study, which means people don't like to dispraise themselves to show politeness. From the proportion we can see the frequency of Modesty Maxim is nearly none, but the Approbation Maxim is about five hundred times as the frequency of Modesty Maxim, which is coincidence with the above analysis result again.

Next is Agreement Maxim. Agreement Maxim is focused on agreeing and disagreeing between self and others. It is also a kind of nature that people like others who have the same or similar opinions, they usually don't like others who against them. Hence, making self and others similarity the most and making the difference least are good ways to show politeness. That's why Agreement Maxim is a useful maxim to show politeness. But people cannot hold the same opinions all the time, and differences are necessary sometimes. Therefore, Agreement Maxim used less than the Tact Maxim and Approbation Maxim. As we can see from the proportion, the frequency of Tact Maxim and Approbation Maxim is more than seven times and five times as the Agreement Maxim.

Lastly, Sympathy Maxim should be proposed. Sympathy Maxim is concerned with showing sympathy or antipathy to others. When others are faced with bad situations, showing sympathy can be a good way to show politeness. But sometimes, some people don't like others to show sympathy to them when they face troubles. Thus, the Sympathy Maxim is also used limitedly and less than Tact Maxim and Approbation Maxim, though it is a useful maxim to show politeness. According to the proportion, the frequency of Tact Maxim and Approbation Maxim is about five times and more than three times as the frequency of Sympathy Maxim, which is suitable to the analysis result.

Apart from all the reasons stated above, several points to explain some maxims in details should also be noticed.

Firstly, Tact Maxim occupies the most important position among the six maxims, because other maxims can be thought as part of Tact Maxim. No matter how generate to cost self's benefit, how humbly to dispraise self, how work hard to praise others, to show similarities and to show sympathy, all these behaviors are aimed at benefiting others to the most degree. Their final goals are the same as the goal of Tact Maxim. Hence, Tact Maxim is the most important maxim in Leech's PP theory and other maxims can be viewed as part of it.

Secondly, Modesty Maxim is sort of related to the cultural background. Because the western culture advocates the idea which people should not dispraise themselves, people living in western culture don't like use Modesty Maxim. But the situation could be much different if the research did in other cultural backgrounds. Thus, Modesty Maxim is not welcomed among people from western cultural background to express politeness.

Thirdly, as mentioned above that the other five maxims can be viewed as part of Tact Maxim. Thus, the identification criterion is not so clear, sometimes it is vague, which makes some sentences hard to identify to which maixm they belong, or leads to the result that some sentences belong to both standard sometimes. Therefore, the six maxims can be used overlapped sometimes.

In a word, why the frequency of each maxim is used differently is because of the benefit. People like gaining benefit the most and costing the least. No matter which maxim is used to show politeness, the purpose of using it is to benefit others the most. Besides, people in the western culture don't like to cost themselves to express politeness. Instead they prefer to benefit others the most. Though Modesty Maxim is related to culture and is not welcomed by people in the western culture, it may have great effect in other cultural backgrounds.

\section{CONCLUSION}

Based on the above results and analysis, the objective of this research will be achieved. Reasons for why such results come out and how often people express their politeness in their daily life in modern American culture will be found. Besides, some limitations and suggestions will also be mentioned.

\section{Findings of the Study}

This research is aimed at using corpus study method to study the PP in $D H$. As the study results show, Tact Maxim is the most useful maxim, followed by Approbation Maxim and Sympathy Maxim. Then Generosity Maxim and Agreement Maxim follow and finally is Modesty Maxim. As for the result of proportion, we can see the number is about 750:100:500:1:100:150.

After viewing the results of this study, we can draw a conclusion that PP is widely used in modern American daily life. But the frequency of each maxim is used differently, because people like benefiting the most and costing the least. So Tact Maxim is used most frequently and is the core conception of PP. Modesty Maxim used the least and is related to the culture effect. Therefore, people in the western culture don't like to cost themselves to show their politeness. Instead they prefer to benefit others the most.

\section{Limitations}

This study has some limitations as follows:

First, the reliability of this study is limited. This research studies the PP only in one TV series, whether this TV series can be a representative of other language materials has not been effectively proved. Besides, only the first season has been chosen to be the study materials, other seasons are not studied yet.

Second, this is an American TV series, which means it has the cultural background limitation. The research is only used in western cultural background, other cultures may not be applied. Apart from what is stated above, this TV series is only related to the daily life conversations, whether the result of this study is suitable for conversations in other situations is not clearly known. 
Third, about PP, different scholars have different opinions. But this study only chooses Leech's theory as the definition of PP, which does not include other scholars' theories.

Finally, the corpus building up work is not entirely objective. Though the criterion is strictly ruled, judge the sentences is a subjective work. Whether the sentences are suitable for the criterion or not sometime depends on personal standards. Thus, it is inevitable that the results of this study affected by some subjective effects.

\section{Suggestions}

Based on the above limitations, further studies should be done in the following aspects.

To begin with, this study can be completed by using the same method and procedure to study other seasons of $D H$. In that case, the researched materials will be enriched and the results will be more precise and complete.

Then, considering that the subjective effects may affect the final results, it is necessary to test the reliability of this study. The further studies can follow the methods and procedure to repeat the study, but the corpus should use the same study material to build up again. In that circumstance, if the result stays unchanged, then the further studies can prove the reliability of this study, otherwise, this study will lose its reliability.

Next, in order to test the reliability of this study, the study materials will be replaced by others, such as conversations in work instead of in daily life, in other cultures instead of in western culture, in websites rather than in TV series. Thus, if study materials are changed and the results stay the same, the reliability can be proved to be high, otherwise this study has a low reliability.

Lastly, the study about PP can be further enriched, no matter what the study material it is. Leech's theory is not perfect; further studies should improve it. What's more, other scholars' PP theories are not considered in this study; further studies can redefine the definition of PP and change the criterion of corpus data selected to do studies.

\section{REFERENCES}

[1] Gerard, V. H. (2012). What is sociolinguistics?. Oxford: Wiley-Blackwell.

[2] Grice, H. P. (1975). Logic and conversation. New York: Academic Press.

[3] Jary, M. (1998). Relevance theory and the communication of politeness. Journal of Pragmatics, 30, 1-19.

[4] Cutting, J. (2007). Pragmatics and discourse (2nd edition). London: Routledge.

[5] Leech, G. N. (1983). Principles of pragmatics. London: Longman Group Ltd.

[6] Sharon, K. D., \& Caroline, H. V. (2011). An Introduction to sociolinguistics. New York: Continuum Publishing Corporation.

[7] Ma, D. (1995). Looking at politeness principles and relevant expressions in communication from perspective of pragmatics. Journal Beijing International Studies University, 2, 1-7.

[8] Zhu, X. (2012). Research on politeness principles - their explanation effects and their constitution in terms of intercultural communication. Master thesis. Beijing: Beijng Jiaotong University.

Jingyu Deng was born in Yichun, China in 1992. She received her BA degree in English studies from Beijing Information Science and Technology University, China in 2013.

She is currently preparing for her MA degree in Beijing, China. Her main research interest is corpus studies.

Xiaoliang Zhou was born in Weifang, China in 1983. He received his MA degree in translation studies from Beijing Foreign Studies University, China in 2008.

He is currently a lecturer in the School of International Studies, Beijing Information Science and Technology University, Beijing, China. His research interests include discourse analysis and educational evaluation. 